\title{
Simulation, design and fabrication of large area implanted silicon two-dimensional position sensitive radiation detectors
}

\author{
K. Aite, P. Hári ${ }^{1}$, W. Bijker and J. Middelhoek \\ IC-technology \& Electronics Group, University of Twente, P.O. Box 217, 7500 AE Enschede, The Netherlands
}

The fabrication process of a two-dimensional position sensitive radiation detector (2-D PSD) with a $4 \mathrm{~cm}^{2}$ active area $1 \mathrm{~s}$ presented. Critical steps in the fabrication are emphasised. Edge effects represent critıcal problems in producing large area ion implanted silicon radiation detectors with low leakage currents and a high breakdown voltage (BV). Two methods have been used to increase the breakdown voltage of the junction: the use of i) floating field limting rings (FFLR) and ii) field plates (FP). Several situations have been simulated analytically and numerically. A comparison of the theoretical results with the measurements realised using the detectors is presented. It is shown that a substantial improvement in the BV of the detector can be achieved by these methods.

\section{Introduction}

The fabrication process of a large area two-dimensional position sensitive detector (2-D PSD) with a total area of $24 \times 24 \mathrm{~mm}^{2}$ and an active area of $20 \times 20 \mathrm{~mm}^{2}$ is presented in this paper. Critical steps in the fabrication are emphasised. This detector is to be used in a magnetic spectrograph employed for surface, interface and thin-fllm analysis, which is being developed at the "Laboratorium voor Algemene Natuurkunde, and Materials Science Centre" of the University of Groningen in The Netherlands [1]. The duolateral type PSD has a resistive layer on both sides and one pair of parallel electrodes on each side. This type of detector has been extensively used as a photodetector [2]. The electrodes on one side of the detector are perpendicular to those

${ }^{1}$ On leave from the Technical Unıversity of Budapest, Hungary. on the opposite side. The front surface also serves for injection of the reverse biased signal to the junction. The duolateral type shows a better linearity than the tetralateral detector which has the four collecting electrodes on one side [2]. We have chosen the duolateral type because of its superior position linearity. However, the fabrication process of this detector is more complex because both sides of the silicon wafer have to be processed.

Fig. 1 shows a three-dimensional view of the duolateral 2-D PSD. The particles bombarding the $\mathrm{p}-\mathrm{n}^{-}$ junction surface of the detector create free electron holes which are separated and swept to the collecting electrodes by the existing electric field. Each particle gives a current pulse which is detected with a chargesensitive amplifier. The position and energy of the particle can be measured with relatively simple circuitry. The implanted $\mathrm{p}$ layer represents a window which is crossed by the impinging particles before they reach the

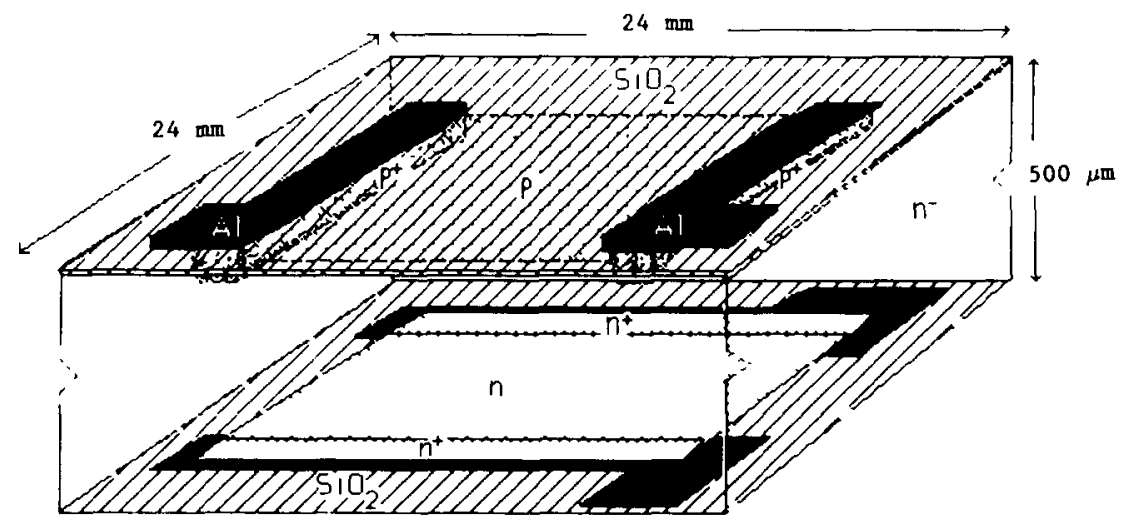

Fig. 1. Three-dimensional view of the duolateral two-dimensional position sensitive detector (2-D PSD). 


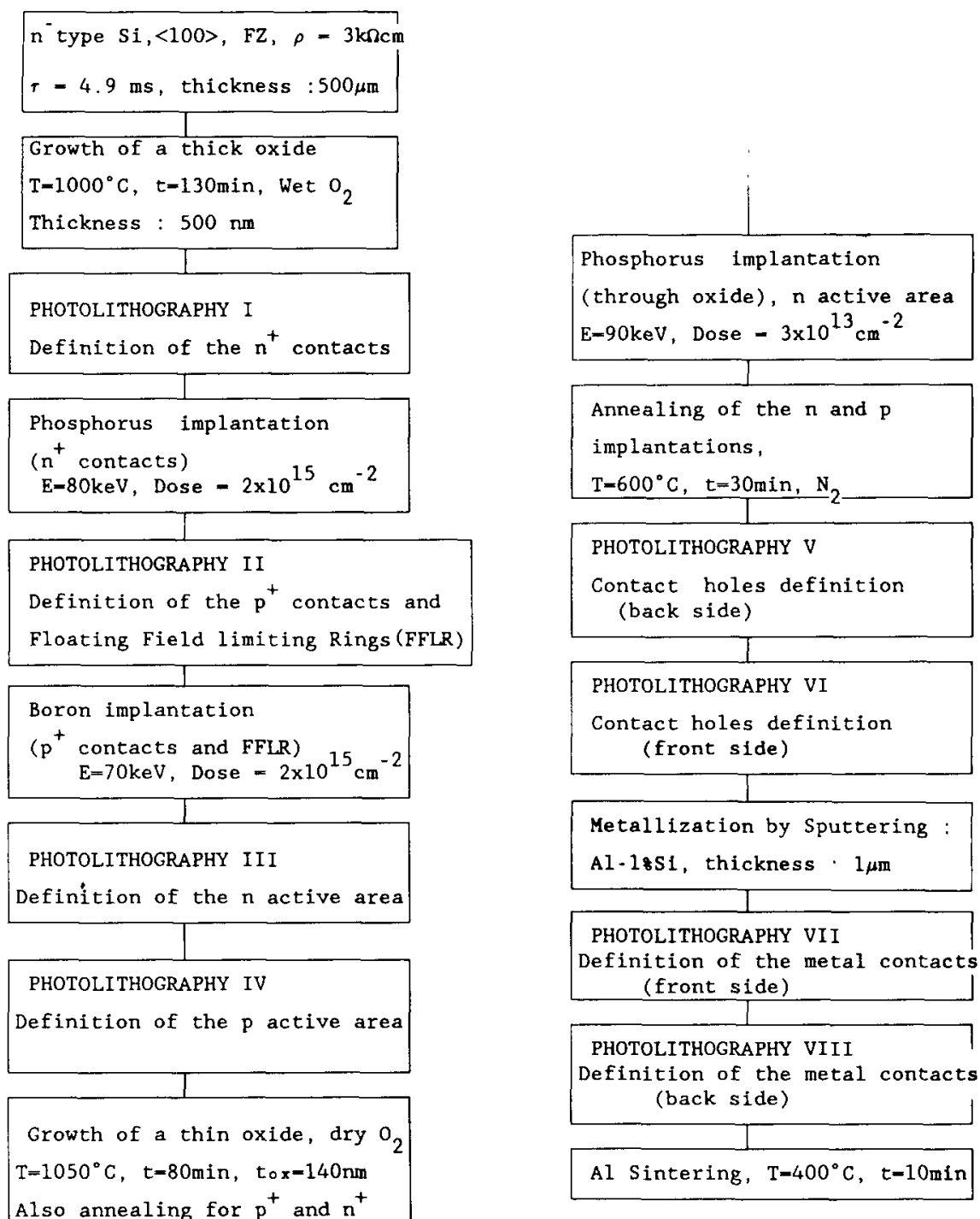

Boron implantation

(through oxide), p active area

$\mathrm{E}=40 \mathrm{keV}$, Dose $=1 \times 10^{13} \mathrm{~cm}^{-2}$

Fig. 2. Flow chart of the fabrication process of the duolateral 2-D PSD

depletion layer. The particles lose part of their energy in this window where a "dead layer" is present. As a consequence there is a decrease in the pulse height and a tail in the radiation spectrum. The dead layer is a heavily damaged layer with a very small carrier lifetime which is estimated to be as small as 100 ps within the first $1000 \AA$ of the surface [3]. Therefore the $\mathrm{p}-\mathrm{n}^{-}$ junction of the detector must be as shallow as possible. Generally, the values achieved in practice are between
0.05 and $0.3 \mu \mathrm{m}$ [4]. It is well known that the breakdown voltage of a planar $\mathrm{p}-\mathrm{n}$ junction is limited by the electric field enhancement due to the curvature effect of the junction plane [5]. The breakdown voltage of a planar $p-n$ junction decreases dramatically with a decrease in the radius of curvature of the junction. The breakdown voltage of a planar $\mathrm{p}-\mathrm{n}$ junction may also decrease when the oxide charge increases excessively (i.e. $Q_{\mathrm{ss}}>5 \times 10^{11} \mathrm{~cm}^{-2}$ ). This represents a severe limı- 
tation for the detector which should support a high reverse bias needed to create a large depletion layer. The point of maximum electric field must be shifted from the surface to the semiconductor bulk in order to increase the breakdown voltage of the silicon radiation detector. Two methods have been used to increase the breakdown voltage of the junction: the use of i) floating field limiting rings (FFLR) and ii) field plates (FP).

Several situations have been simulated analytically as well as numerically by using the two-dimensional device and process simulation program TRENDY [6]. A comparison of the theoretical results with the measurements realised using the detectors will be presented. It is shown that a substantial improvement in the breakdown voltage of the detector can be achieved by these methods.

\section{Fabrication process}

Fig. 2 shows the flow chart of our 2-D PSD. Eight masks were used for the fabrication of the detector: four for the front side which contains the $\mathrm{p}-\mathrm{n}^{-}$junction and four for the back side. Float zone (FZ) silicon wafers polished on both sides were processed and a 2 $\mu \mathrm{m}$ photoresist layer was used to protect the unprocessed side against unwanted etching and scratching. The choice of a highly ohmic n-type silicon with a resistrvity of $3 \mathrm{k} \Omega \mathrm{cm}$ was dictated by the demand for the lowest possible capacitance and the largest possible depletion layer. A $\langle 100\rangle$ oriented silicon substrate was used because the lowest values for fixed oxide charge density and interface-trapped charge density are obtained for this type of crystal orientation. The leakage current $I_{r}$ of the detector is mainly the sum of the three components: i) the saturation current due to minority carriers, 1i) the generation current which is mainly due to recombination centers constituted by impurity atoms or structural imperfections associated with energy levels in the forbidden band of silicon, and iii) the surface leakage current. The components i) and iii) are neglected here because the detector is fully depleted; thus there are no diffusion currents and the surface is passivated. However, in practice these contributions may still be of varying importance. The leakage current $I_{\mathrm{r}}$ is then given by the generation current $I_{\mathrm{g}}$ which is inversely proportional to the minority carrier lifetime $\tau$ :

$I_{\mathrm{r}} \cong I_{\mathrm{g}}=A d q n_{\mathrm{V}} / 2 \tau$,

where $A$ and $d$ represent the area and the depletion layer depth of the detector, respectively. The constants $q$ and $n_{1}$ are the values of the electronic charge and the silicon intrinsic density, respectively. Therefore, according to eq. (1) it is important to have the highest carrier lifetime possible in order to minimize the leakage current. The amount of high temperature treatments which may lead to a dramatic and irreversible degradation of the bulk carrier lifetime [7] should be reduced. The carrier lifetime of our starting material was $4.9 \mathrm{~ms}$ as given by the manufacturer Topsil. Furthermore, thorough cleaning must be done before each high temperature step in order to avoid unwanted impurity incorporation into the material. In fact, metallic impurities diffuse rapidly into the bulk silicon at high temperatures and introduce high recombination center densities which degrade the carrier lifetime. The silicon wafers were cleaned following a standard cleaning procedure using fuming $\mathrm{HNO}_{3}$ and boiling $65 \% \mathrm{HNO}_{3}$. Etching with $\mathrm{HF}$ as a final step was not performed because it has been reported that this step significantly enhances the rate of impurity adsorption on a silicon surface [8].

The field oxide was grown in wet $\mathrm{O}_{2}$. This leads to a higher growth rate, thus minimizing the duration of the high temperature treatment. Compared to growth in dry $\mathrm{O}_{2}$ this y1elds more interface states and leads to surface leakage current. However, the last oxide, which is also used as a mask to obtain a shallow implantation, was grown in dry $\mathrm{O}_{2}$ which results in $\mathrm{SiO}_{2}$ with a high quality $\mathrm{SiO}_{2} / \mathrm{S}_{1}$ interface. It was also important to keep the furnace tubes clean prior to any high temperature treatment of the silicon wafers. For this purpose, prior to any high temperature step, the furnace tubes were cleaned at $1100^{\circ} \mathrm{C}$ with a mixture of $\mathrm{O}_{2}$ and trichloroethane $\left(\mathrm{C}_{2} \mathrm{H}_{3} \mathrm{Cl}_{3}\right)$ [9] in order to remove the metallic impurities. Moreover, the processed silicon wafers were cooled to room temperature at a slow rate of $-2^{\circ} \mathrm{C} / \mathrm{min}$ to preserve the carrier lifetime.

A high phosphorus dose of $2 \times 10^{15} \mathrm{~cm}^{-2}$ with an energy of $80 \mathrm{keV}$ was used to implant the $\mathrm{n}^{+}$low ohmic contacts at the back side of the detector. The $\mathrm{p}^{+}$ contacts on the front side were implanted at $70 \mathrm{keV}$ with a boron dose of $2 \times 10^{15} \mathrm{~cm}^{-2}$. The resulting sheet resistances were $72 \Omega / \square$ for the $\mathrm{p}^{+}$layer and $30 \Omega / \square$ for the $\mathrm{n}^{+}$layer as calculated by the program SUPREM-III [10]. The sheet resistance calculated with the same program for both the $\mathrm{p}-\mathrm{n}^{-}$and $\mathrm{n}-\mathrm{n}^{-}$junctions was $30 \mathrm{k} \Omega / \square$. This value has been chosen in order to obtain a good signal/noise ratio for the detector. The junction depth simulated by SUPREM-III was $0.14 \mu \mathrm{m}$ for the $\mathrm{p}-\mathrm{n}^{-}$junction and $0.17 \mu \mathrm{m}$ for the $\mathrm{n}-\mathrm{n}^{-}$ junction. We should mention that the UV light exposure of the photoresist was not done in a clean room. The wafer stepper available in our clean room could not process such large area chips $\left(24 \times 24 \mathrm{~mm}^{2}\right)$. Therefore, a mask aligner installed temporarily outside of the clean room was used. This fabrication step had a dramatic influence on the leakage current which was enhanced by the generation of a large amount of local defects. However, in terms of leakage current magnitude, the efficacy of our fabrication process could be evaluated by measuring a few selected tiny diodes $\left(100 \times 100 \mu \mathrm{m}^{2}\right)$, and values in the range of $1-25 \mathrm{nA} / \mathrm{cm}^{2}$ were found for a 
depleted zone of $100 \mu \mathrm{m}$. Clearly, this equipment limitation did not affect the emphasised point of our study which was the improvement of the breakdown voltage.

\section{Breakdown voltage with and without FFLR}

Fig. 3 shows the measured reverse current-voltage characteristic of a 2-D PSD with an active area of $20 \times 20 \mathrm{~mm}^{2}$ and without any guard ring at the edge of the main junction. Due to its low breakdown voltage, such a detector cannot support a high reverse voltage which is required for the creation of a large depletion layer. The leakage current reaches prohibitive values of about $0.1 \mathrm{~mA}$ at a reverse bias of $100 \mathrm{~V}$. It is well known that the breakdown voltage of a planar $p-n$ junction is limited by the curvature effect of the junction plane. This limitation is severe for shallow junctions $\left(x_{j}<0.25 \mu \mathrm{m}\right)$ which can have their breakdown voltage reduced to a few volts. The breakdown voltage of the $\mathrm{p}-\mathrm{n}$ junction can be improved by shifting the point of maximum electric field to a region far from the surface.

A method commonly applied for this purpose in high-voltage power devices is using floating field limiting rings (FFLR) [11]. The FFLR method is illustrated in fig. 4 where the equipotential lines present a low curvature at the outer edge of the ring; therefore a lower electric field is obtained after punchthrough. We used the analytical model developed by Chang and Sune [12] to calculate the optimum spacing between the main junction and the FFLR in the case of one shallow ring formed by the same ion implantation as used for the main junction. The model solves the two-dimensional

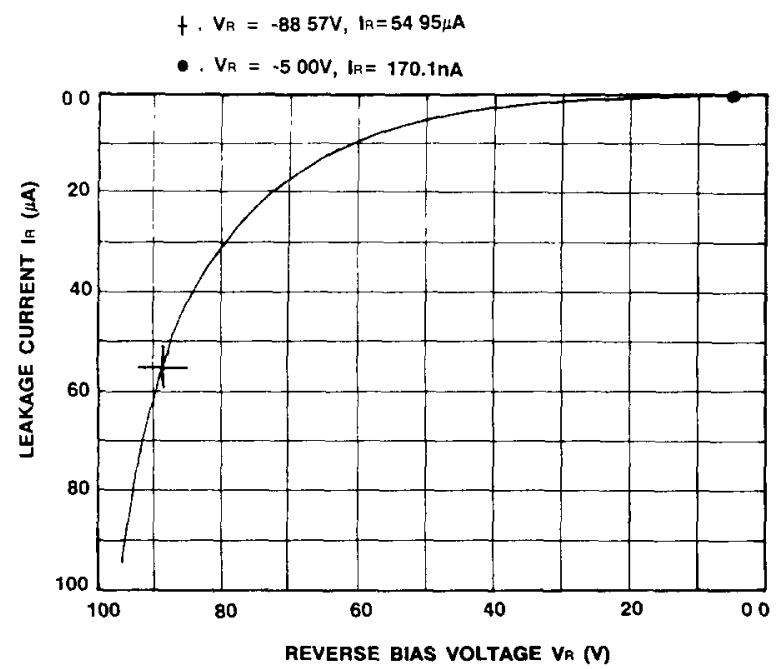

Fig. 3. Reverse current-voltage characteristic of a 2-D PSD with an active area of $20 \times 20 \mathrm{~mm}^{2}$ and without any guard ring at the edge of the main junction.

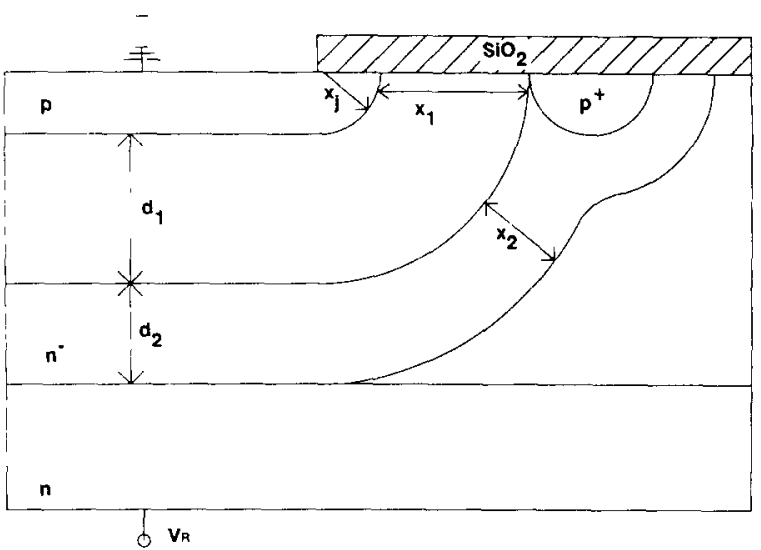

Fig. 4. Cross section of the $\mathrm{p}-\mathrm{n}^{-}-\mathrm{n}$ dode with one floating field limiting ring. The equipotentials are illustrated for the cases before punchthrough (depletion zone $\leq x_{1}$ ) and beyond punchthrough (depletion zone $\geq x_{1}$ ).

Poisson equation in order to obtain the electric field distribution. The structure considered was approximated by the conventional cylindrical junction. Our detectors were designed with edges of $135^{\circ}$ and any angle of $90^{\circ}$ was avoided, so the spherical junction case could be neglected in our calculations. The resulting electric field distribution is used to solve the ionisation integral which is related to the breakdown voltage. Fig. 5 shows the calculated ionisation integrals for the cases before punchthrough (KM) and beyond punchthrough (KR) versus the spacing $\left(x_{1}\right)$ between the FFLR and the main junction. The ionisation integral KM decreases with $x_{1}$ while $\mathrm{KR}$ increases with $x_{1}$. The point where KM and KR intersect gives the value of $x_{1}$ for which the value of the breakdown voltage of the $\mathrm{p}-\mathrm{n}^{-}$junction is optimum. The analytical model allows an easy determination of the optimum spacing between the main junction and the ring, but it does not provide any quantitative information about the breakdown voltage

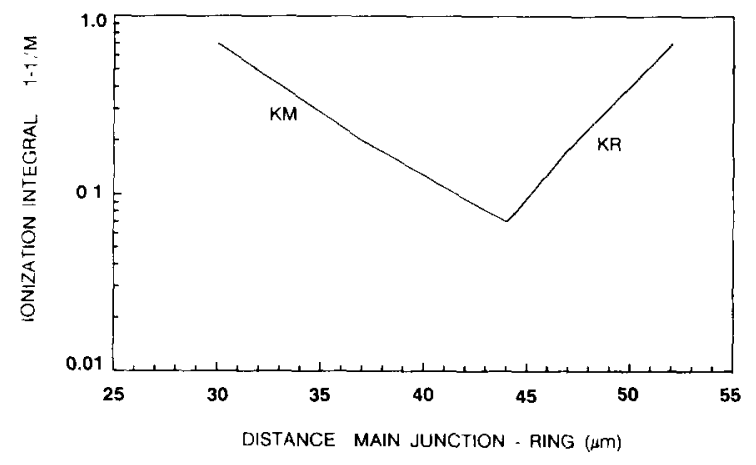

Fig. 5. Ionisation integrals for the cases before punchthrough (KM) and beyond punchthrough (KR) vs the spacing between the FFLR and the main junction. A ring has the same depth as the shallow main junction. 


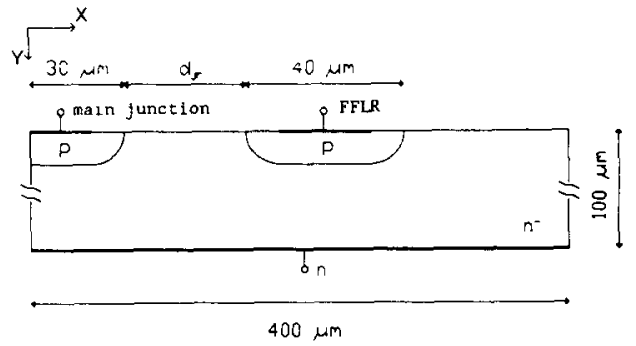

(a)
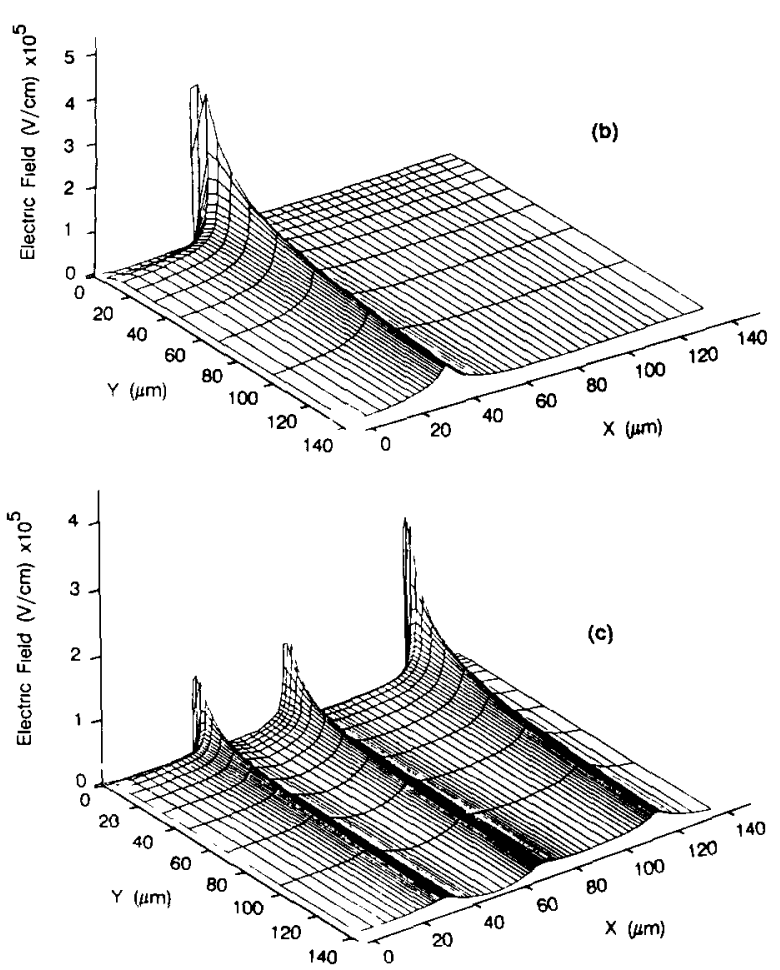

Fig. 6. Two-dimensional simulation of the electric field distribution for a structure with one FFLR having the same depth as the shallow main junction $\left(x_{j}=0.24 \mu \mathrm{m}\right)$. (a) Cross section of the structure, (b) electric field distribution without FFLR, (c) electric field distribution with one FFLR at a distance $d_{j \mathrm{r}}=30 \mu \mathrm{m}$ from the main junction.

improvement. For this reason, the two-dimensional device and process simulation program TRENDY has been used to simulate both the breakdown voltage increase and the optimum spacing between the main junction and the FFLR. As for the analytical calculations, the conventional cylindrical junction case was considered. The depth of the main junction was kept at $0.24 \mu \mathrm{m}$.

Fig. 6a shows a cross-section of the structure used in our simulations. The oxide charge was not taken into account in our calculations. The relative variation of the breakdown voltage obtained with a surface charge of
Table 1

Different cases of junctions with one and two FFLRs: opt1mum positions of the rings and percentage of breakdown voltage improvement.

\begin{tabular}{llll}
\hline $\begin{array}{l}\text { Number } \\
\text { of FFLR }\end{array}$ & $\begin{array}{l}\text { Junction depth } \\
\text { of the FFLR } \\
{[\mu \mathrm{m}]}\end{array}$ & $\begin{array}{l}\text { Optimum distance } \\
\text { main junction- } \\
\text { first FFLR } \\
d_{\mathrm{jr}}[\mu \mathrm{m}]\end{array}$ & $\begin{array}{l}\text { BV improve- } \\
\text { ment } \\
{[\%]}\end{array}$ \\
\hline 1 & 0.24 & 45 & 8.5 \\
2 & 0.24 & $\begin{array}{l}0<d_{\mathrm{Jr}}<5 \\
d_{\mathrm{rr}^{\prime}}=10\end{array}$ & 20 \\
1 & 1.1 & $\begin{array}{l}0<d_{\mathrm{J}}<5 \\
0<d_{\mathrm{Jr}}<5\end{array}$ & 30 \\
2 & 1.1 & $d_{\mathrm{Jr}^{\prime}}=45$ & 60 \\
\hline
\end{tabular}

$5 \times 10^{11} \mathrm{~cm}^{-2}$ is less than 5\% [13]. Our approximation is reasonable because the measured interface state density of our oxide is only $5.4 \times 10^{10} \mathrm{eV}^{-1} \mathrm{~cm}^{-2}$. A sharp electric field peak exists at the surface and at the edge of the main junction when no FFLR is used (fig. 6b). Three electric field peaks are obtained when one FFLR is placed at a distance of $30 \mu \mathrm{m}$ from the main junction (fig. 6c). The three peaks are located at the outer edges of the main junction and the FFLR. The ring acts as a divider of the surface electric field existing between the main junction and the FFLR. The spacing leading to the highest breakdown voltage corresponds to the situation where three equivalent peaks are obtained. Table 1 summarises the results obtained for several situations with one and two FFLRs. The depth of the main junction was kept constant at $0.24 \mu \mathrm{m}$ for all the simulations. The optimum spacing between the ring and the main junction is found to be $45 \mu \mathrm{m}$ for the case of one shallow ring. This result is in good agreement with the analytical result $(44 \mu \mathrm{m})$. The breakdown voltage improvement is only $8.5 \%$ in this case. The breakdown

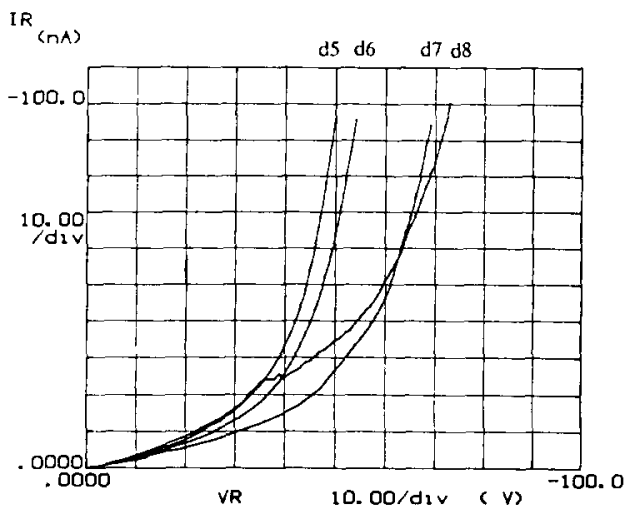

Fig. 7. Reverse current-voltage characteristic of a $0.5 \times 0.5$ $\mathrm{mm}^{2}$ diode. A ring has the same depth as the shallow junction. The distance main junction-ring is variable: $d_{5}=20 \mu \mathrm{m}$, $d_{6}=30 \mu \mathrm{m}, d_{7}=40 \mu \mathrm{m}, d_{8}=50 \mu \mathrm{m}$. 


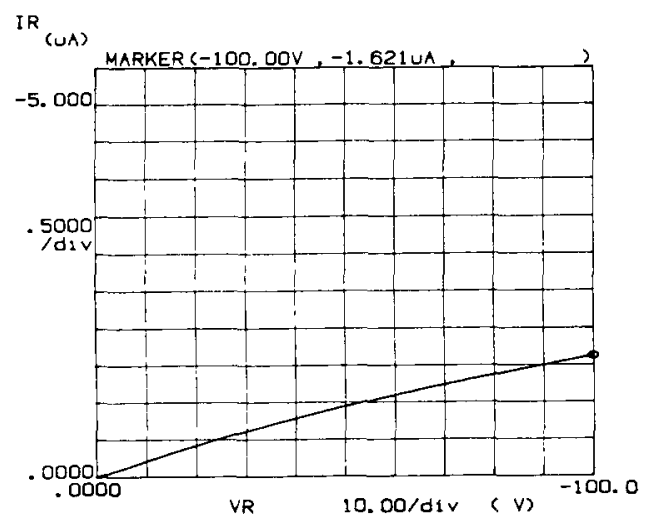

IR (UA)

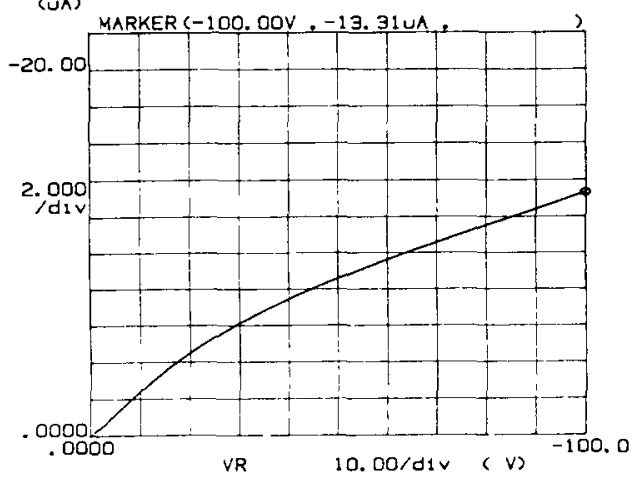

(b)

Fig. 8. Reverse current-voltage of duolateral 2-D PSDs with two deep rings $(11 \mu \mathrm{m})$ positioned at the edge of the main junction. (a) Detector with an active area of $10 \times 10 \mathrm{~mm}^{2}$, (b) detector with an active area of $20 \times 20 \mathrm{~mm}^{2}$.

voltage is increased by $60 \%$ when two deep rings (1.1 $\mu \mathrm{m})$ are used: the first ring is positioned at a distance of $0<d_{\mathrm{Jr}}<5 \mu \mathrm{m}$ from the main junction and the distance between the two rings is $45 \mu \mathrm{m}$.

Fig. 7 shows the experimental reverse current-voltage characteristics for small diodes $\left(0.5 \times 0.5 \mathrm{~mm}^{2}\right)$ with one shallow ring positioned at different distances from the main junction. The highest value of the breakdown voltage is obtained for a diode having a ring positioned at a distance of $50 \mu \mathrm{m}$ from the main junction. This result is in good agreement with the simulated value of $45 \mu \mathrm{m}$ when all the experimental errors are taken into account. Figs. $8 \mathrm{a}$ and $8 \mathrm{~b}$ show the reverse current-voltage characteristics obtained for large detectors having two deep rings $(1.1 \mu \mathrm{m})$ at the edge of the main junction. No breakdown is observed for reverse voltages as high as $150 \mathrm{~V}$. The substantial improvement of the breakdown voltage can be clearly seen by comparing figs. 3 and $8 b$.

\section{Breakdown voltage with a field plate}

"Field plates" are widely used for high-voltage power devices. A p-n junction with a field plate is a gate-controlled diode. Field plates have been also used for implanted silicon detectors (see for example ref. [14]). In the case of an n-type substrate a negative potential applied at the field plate creates a depletion layer under the $\mathrm{SiO}_{2}$ layer. Consequently, the depletion region of

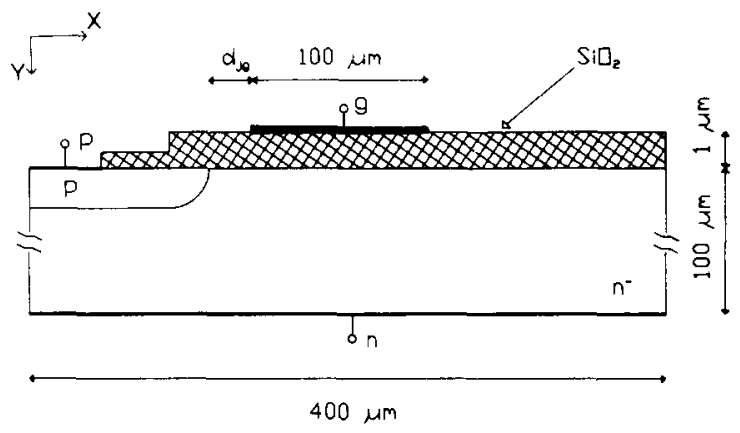

(a)

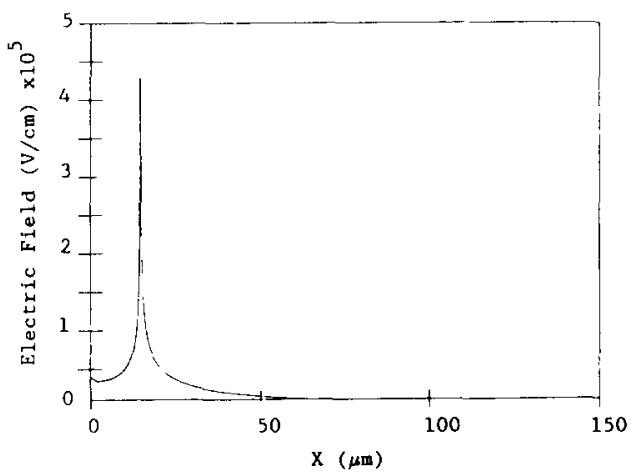

(b)

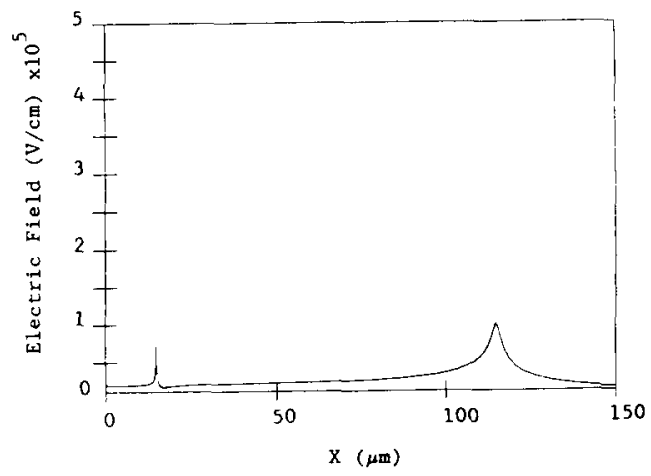

(c)

Fig. 9. Simulation of the electric field distribution for a structure with a field plate. (a) Cross section of the structure, (b) surface electric field distribution with a floatıng field plate, (c) surface electric field distribution with a field plate biased with a voltage of $-200 \mathrm{~V}$. 


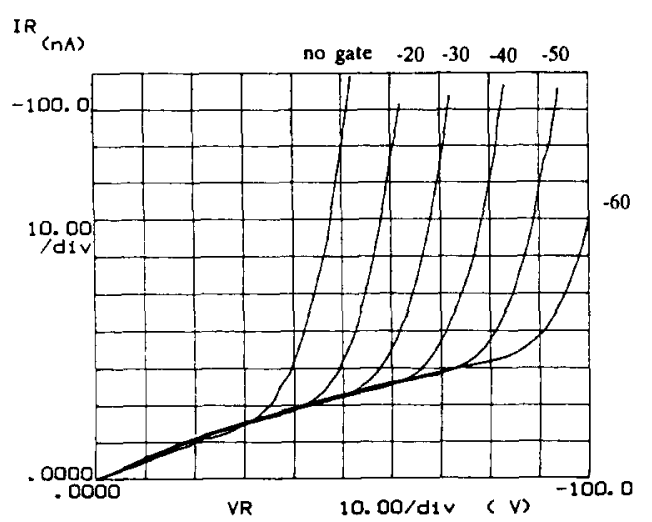

Fig. 10. Reverse current-voltage characteristic of a $0.5 \times 0.5$ $\mathrm{mm}^{2}$ diode having a field plate biased with an increasing potential.

the main junction is expanded laterally. Therefore, an increase in the effective radius of curvature is observed, so a higher breakdown voltage is expected for the junction. When the field plate is biased positively, the surface under the $\mathrm{SiO}_{2}$ is in accumulation which causes a decrease in the junction's radius of curvature; therefore the breakdown voltage becomes lower.

The structure represented in fig. $9 \mathrm{a}$ has been used to simulate with TRENDY the electric field distribution at the edge of the junction that has a field plate. Note that a spacing $d_{\mathrm{gg}}$ is left between the edge of the junction and the field plate. This spacing should be kept lower than the depth of the deep depletion zone of the MOS capacitor formed by the $\mathrm{SiO}_{2}$ in order to have the gate control effect. Values of $\mathrm{O} \leq d_{\mathrm{Jg}} \leq 5 \mu \mathrm{m}$ were used in our simulations. Similarly to the case of FFLR simulations, the oxide charge was not taken into account. Fig. $9 b$ shows a sharp electric field peak at the surface edge of the junction when the field plate is floating. Two electric field peaks with substantially lower intensities than in the preceding case are obtained when the field plate is biased with a voltage of $-200 \mathrm{~V}$ (fig. 9c). According to fig. $9 \mathrm{c}$, the field plate behaves like a voltage divider. The breakdown voltage is increased by $75 \%$. Finally, fig. 10 shows the current-voltage characteristic of a $0.5 \times 0.5 \mathrm{~mm}^{2}$ diode having a field plate biased with an increasing voltage. The breakdown voltage increases gradually with the negative voltage of the field plate.

\section{Conclusions}

The fabrication process of a large duolateral 2-D PSD has been presented with emphasis on the critical steps. Such a detector requires a shallow junction which represents a severe limitation to the breakdown voltage. It is shown that a $60 \%$ improvement in the detector breakdown voltage can be obtained by implementing two deep floating field limiting rings $(1.1 \mu \mathrm{m})$ positioned as follows:

distance main junction-first ring: $0<d_{\mathrm{Jr}} \leq 5 \mu \mathrm{m}$; distance first-second ring: $45 \mu \mathrm{m}$.

The breakdown voltage of the detector can be improved by $75 \%$ when a field plate biased with a voltage of $-200 \mathrm{~V}$ is used.

\section{References}

[1] D.O. Boerma, F Labohm and J.A. Reinders, Nucl. Instr. and Meth. B50 (1990) 291.

[2] H.J. Woltring, IEEE Trans. Electron Devices ED-22 (Aug. 1975) 581.

[3] J. Lindmayer and J.F. Allison, Conf. Rec. 9th IEEE Photo. Spec. Conf., Silver Spring (1972) p. 83.

[4] P. Burger, K. De Backker and W. Schoenmaekers, Solid State Imagers and Their Applications, Proc. SPIE 591 (1985) 38.

[5] S.M. Sze, Physics of Semuconductor Devices (Wiley, New York, 1981)

[6] E. van Schie, Ph.D. Thesis, University of Twente, The Netherlands (1990).

[7] E. Susi, G. Lulli, and L. Passari, J. Electrochem. Soc. 134 (1987) 1239.

[8] S.I. Raider, R. Flitsch and M.J. Palmer, J Electrochem. Soc. 122 (1975) 413.

[9] R.K. Bhan, S.K Lomash, P.K. Basu and K.C. Cahabra, J. Electrochem. Soc., 134 (1987) 2826, and references therein.

[10] S.E. Hansen, Stanford University Process Engineering Models Program, SUPREM-III User's Manual (1982).

[11] Y.C. Kao and E.D. Wolley, Proc. IEEE 55 (1967) 1409.

[12] C.Y. Chang and C.T. Sune, IEEE Electron Devices Lett. EDL-7 (1) (1986) 35.

[13] V. Borsson, M. Le Helly and J.P. Chante. IEEE Trans. Electron Devices ED-33 (1) (1986) 80.

[14] C. Goessling, E.H.M. Heijne, P. Jarron, H.A. Parker, Redaelli and L. Rossi, IEEE Trans. Nucl. Sci. NS-33 (1) (1986) 272.

\section{Discussion}

C. Gössling (Univ. Dortmund): What is the position resolution that you can reach?

K. Aite: On a $1 \mathrm{~cm} \times 1 \mathrm{~cm}$ detector, cooled with liquid nitrogen, we achieved with charge division a $0.1 \mathrm{~mm} \times 0.1 \mathrm{~mm}$ resolution for $1 \mathrm{MeV}$ ions.

P. Burger (Canberra): Did you take the oxide charge into account in your simulation? Did you measure the oxide charge in your processing?

K. Arte: We did not take oxide charge into account in the program, but the passivation makes it unnecessary to do so, because its value should be very low. The measured interface state density $N_{\mathrm{ss}}$ is $5.4 \times 10^{10} \mathrm{eV}^{-1} \mathrm{~cm}^{-2}$.

A. Hoeberechts (Philips): What is the oxide thickness?

K. Aite: The field oxide is $500 \mathrm{~nm}$ thick. 
L. Bosisio (INFN, Pisa): What was the calculated breakdown voltage in your configuration?

$\mathrm{K}$. Aite: The calculated breakdown voltage is $160 \mathrm{~V}$ and measured breakdown voltage is $150 \mathrm{~V}$. This difference between the theoretical and experimental results is not excessive and may be explained by the oxide charge which is not taken into account in our simulations.

V. $\operatorname{Re}$ (Univ. Pisa): What is the charge collection time? K. Aite: I do not know.
P. Borgeaud (Saclay): What is the purpose of this detector? $\mathbf{K}$. Aite: This detector is to be used in a magnetic spectrograph installed at a $6 \mathrm{MeV}$ Van de Graaff accelerator.

H. Rijken (Univ. Eindhoven): What is the thickness of the dead layer?

K. Aite: Between 0.1 and $0.12 \mu \mathrm{m}$ measured by angular variation. 